\title{
Pierre Maurice Gy (1924-2015) Dr Pierre M. Gy's work: a 60-year revolution in the world of sampling statistics
}

n 1968, at MINEMET, I was introduced to Pierre's work. The intellectual level, scientific value and impeccable Cartesian approach of his work fascinated me. Immediately, I developed a passion for the Theory of Sampling, admiring the work of a man I had never met. His work could have been very useful at the French Atomic Energy Commission, where I did a lot of sampling to monitor radioactive contamination.

In 1981, we met for the first time in the USA, and it was instant friendship. I started my consulting business in 1985, in parallel with Pierre's work. My respect for Pierre's work remained unshakable, and I would like to share this with all of you who will dearly miss this remarkable mentor.

Many sampling theories were created in the past: I am familiar with most of them. None of them ever reached the depth, quality of thinking and completeness as Pierre's Theory does, dividing a complex problem into a flawless sum of smaller problems that can be solved one by one. Thank you Pierre for the Theory of Sampling, the only valid Theory of Sampling, the only one that should be part of sampling standards. But, there is much more to the man.

In a remarkable way, using Matheron's work, Pierre created a world of his own in variography as applied to metallurgical and chemical processes, leading to the new concept of Chronostatistics. It is a cousin of Geostatistics, as applied to process control and metallurgical accounting. The scientific breakthrough was awesome. The modern worlds of Statistical Quality Control, Statistical Process Control and Six Sigma offer valuable concepts to improve quality and productivity. Their statistical methodology would greatly benefit from the impressive effectiveness of Chronostatistics and its promising future. Thank you Pierre for the new world of Chronostatistics.

A direct consequence of Chronostatistics was for Pierre to enter the world of blending. Within a few years, he was able to deliver the world of blending from paradoxical beliefs, and help that science to focus on the relevant variability. The impact on blending design, engineering and implementation was a breakthrough to manufacturers. Thank you Pierre for a logical, coherent theory of blending.

Pierre's enormous experience in sampling was the ideal ground for creating new ideas. Pierre created the concept of Proportional Sampling. It was a revolutionary idea companies took for a scientific curiosity with no practical applications. Indeed, it cannot be applied when $75 \%$ of the sampling equipment available on the world market is flawed, by design, by the way it is built, by the way it is maintained and the way it is used. Proportional Sampling is the future of good, reliable sampling equipment. It is only a matter of time before Proportional Sampling becomes a very popular way to perform a better job in sampling. Thank you Pierre for the theory of Proportional Sampling.

But, a remarkable man like Pierre would be an incomplete person without a passion for something other than sampling. We all need hobbies, as an anchor to cleanse our mind, reach serenity and at the end of the day come back to what we do best, and perform well again. My hobby is archaeology and writing novels. Pierre's passion is the tranquillity of high mountains, and the beauty of little wild flowers. The contrast between the mind of a great master in sampling, and the fragile, beautiful, little wild flower is the perfect image of Dr Pierre M. Gy's mind. If most men were given this extraordinary ability of moving, at any time, from charismatic achievement to humbleness, the entire world would be a better place today. Thank you my dear friend and mentor for combining extraordinary talent with humbleness and beauty.

Pierre's work is superb, has enormous momentum and will inevitably conquer many industries. Standards around the world are still either shy or resistant to the Sampling Theory, because of ignorance or because of conflicts of interest. Sixty years of patience and hard work are beginning to pay off within academic institutions. Resistance from statistical circles that are ignorant of the Theory of Sampling will soon become futile.

The very last time I saw Pierre in July 2015, as I was departing from our short visit to him in Bordeaux after the WCSB7 conference, he kissed my hand and murmured these words: "we have nice troops now!"

Indeed, his legacy will endure because of the formidable body of knowledge and talents accumulated and carried on by the World Conference on Sampling and Blending, its medallists, its technical committees, its publications and its academic and practical achievements.

On a last note for what it's worth, Dr Pierre M. Gy was a silent genius; and it's a shame that he was not recognised more by being honoured for his achievements as a "Chevalier de la Legion d'Honneur".

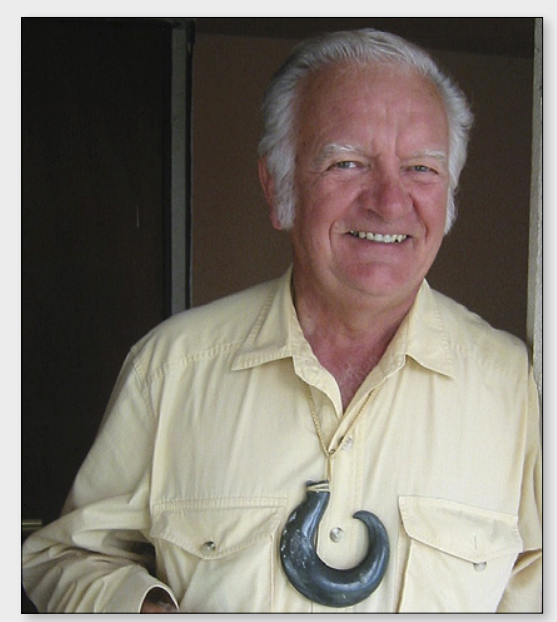

Dr Francis Pitard is a recipient of the prestigious Pierre M. Gy's Gold Medal for excellence in teaching and promoting the Theory of Sampling. 